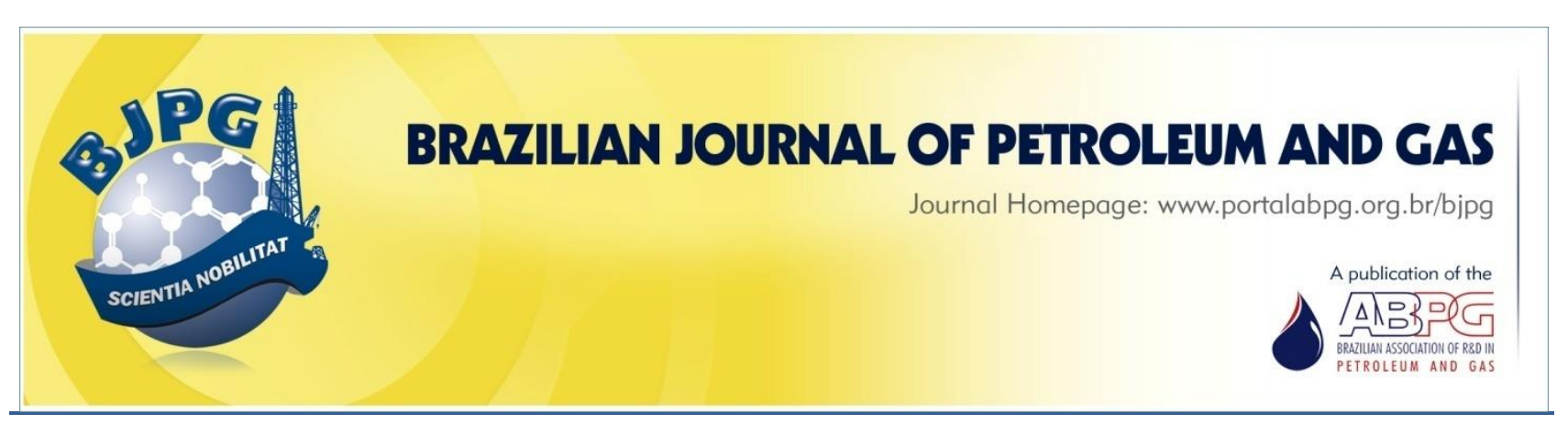

\title{
PRESSURE DROP IN LIQUEFIED PETROLEUM GAS LAMINAR FLOW IN CYLINDRICAL ELLIPTIC PIPES
}

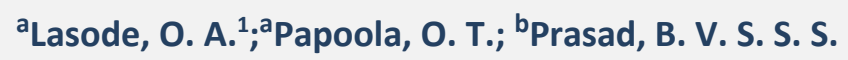 \\ ${ }^{\mathrm{a}}$ Department of Mechanical Engineering, University of Ilorin, Ilorin, Kwara State, Nigeria \\ ${ }^{b}$ Department of Mechanical Engineering, Indian Institute of Technology, Madras, Chennai, India
}

\begin{abstract}
This work investigated Liquefied Petroleum Gas (LPG) flow in cylinders of elliptic cross-section. The LPG found in Nigeria contains mainly butane with varying percentages of propane. Commercial code FLUENT, which uses the finite volume method, was used to solve fluid flow governing equations. Very little attention has been paid to LPG flow in cylindrical elliptic pipes. Results of flow parameters of velocity and pressure were presented. Results showed that the pressure drop for LPG flow in elliptic pipes was higher than the ones of the circular pipes for the same cross-sectional area. This finding is relevant because the pressure drop is related to the power needed to drive the flow. Results showed that the velocity increased towards centre of the pipe at all cross-sections, and also increased towards the outlet of the pipe.
\end{abstract}

\section{KEYWORDS}

numerical study; pressure drop; liquefied petroleum gas; elliptic pipes

\footnotetext{
${ }^{1}$ To whom all correspondence should be addressed.

Address: Department of Mechanical Engineering, University of Ilorin, P.M.B. 1515, Ilorin 240003, Nigeria. ZIP Code: 240003 | Telephone: +234-805-564-7409|e-mail:oalasode@yahoo.com; lasodeoa@gmail.com doi:10.5419/bjpg2013-0014
} 


\section{INTRODUCTION}

Nigeria is a producer of crude oil and other petroleum products. It also produces large volumes of associated gas, rich in Natural Gas Liquids (NGL), and Liquefied Petroleum Gas (LPG). In 2005, it had an estimated reserve of gas of about 5.377 trillion standard cubic meters, which made Nigeria one of the countries with largest reserves in the world (Chikwendu, 2011). Nearly half of this reserve was flared. The quantity of LPG produced in 2003, extracted from crude oil and natural gas, was estimated to be 4 million tonnes (Agboade, 2012). Natural gas purification produces about 55 per cent of all LPG, while crude oil refining produces about 45 per cent worldwide (TCPA, 2008).

LPG is widely recognised as a clean fuel, being versatile, environmentally friendly, and easily transportable. Its main composition is hydrocarbon, containing 3 (propane, $\mathrm{C}_{3} \mathrm{H}_{8}$ ) to 4 (butane, $\mathrm{C}_{4} \mathrm{H}_{10}$ ) carbon atoms depending on the source of origin. It is a gas at atmospheric pressure, but can be liquefied when pressure is applied or when the temperature is reduced sufficiently. LPG is stored in steel containers, cylinders, or tanks. When LPG is used, some of the pressure in the container is released. Part of the LPG, then, boils to produce vapour. Heat is needed to convert the liquid to vapour (known as the latent heat of vaporisation). As the liquid boils, it draws the heat energy from its surroundings (LPG, 2012).

The composition of LPG commonly available in Nigeria is a mixture of propane and butane with the percentages varying between $1.4 / 98.5$ to 23.0/76.9 propane/butane depending on the refinery (Olorunmaiye, 1997).

A study by the World Bank Oil and Gas Division revealed a very low per capita usage of LPG in Nigeria in comparison to other neighbouring countries in West Africa (WBOGD, 2001). The consumption collapsed to 50,000 tonnes in 2003. Most of the LPG was imported. The average consumption rate in Nigeria is estimated to be $0.5 \mathrm{~kg} / \mathrm{h} /$ year, while in the other Africa sub-regions, it is about $3.7 \mathrm{~kg} / \mathrm{h} /$ year. The low consumption rate of LPG in homes in Nigeria comes from the fact that its supply is unreliable, not easily accessible, and costly.

The main mode of transporting LPG is either using special pressure containers or transporting it to storage areas through pipelines. Knowledge of the flow behaviour of the fluid in different geometries will assist researchers in designing these pipes and also determining the pumping power necessary for pushing the fluid from the point of extraction to the point of refining and distribution. The circular duct is the most used geometry in fluid flow and heat transfer devices (Shah and Bhatti, 1987). Most pipelines are built with circular cross-sections because they have a simpler geometry with lower pressure drop during flow (Cade et al., 2010). Flow inside pipes is a typical example of internal flow. Internal flows are of paramount interest in engineering because of their various applications ranging from the design of heat exchangers to oil and gas pipelines. Elliptic geometry is a useful family of ducts that vary from a narrow lenticular passage to a circular one (Shah and Bhatti, 1987). There is limited knowledge of the fluid flow field in this kind of duct surface. LPG is used widely in industries in Nigeria. An understanding of the velocity field and the pressure drops in pipe with LPG flowing through it will help in the design of the pipes. Shah and Bhatti (1987) and Rohsenow and Harnett (1973) presented various results on hydrodynamically developing and developed flow in ducts of various cross sections. The results of Cade et al.'s (2010) study of natural gas laminar flow in cylindrical pipes with elliptic cross-sections show velocity and pressure prediction for various aspect ratios. Velusamy and Garg (1993) presented a numerical solution using control volume approach to solve fluid flow problems in an elliptic duct. They considered aspect ratios with a range of 0.1 to 0.99. Their results showed that the ratio of the entry length in an elliptic duct to that in a circular duct with radius equal to semi-major axis of elliptic duct is nearly equal to the aspect ratio of the duct. The total pressure defect was also found to be independent of aspect ratio. Lasode et al. (2013) engaged in the numerical study of liquefied petroleum gas laminar flow in cylindrical elliptic pipes. Their results presented velocity and pressure variations of various aspect ratios. Bhatti (1983) used a closed form analytical approach to study laminar flow of Newtonian fluid in the entrance region of elliptic ducts. The analysis entailed the solution of integral forms of mass and momentum balance equations which was based on the KarmaPohlhausen integral method. The result showed that pressure defect is independent of aspect ratio. The current paper aims at investigating pressure 


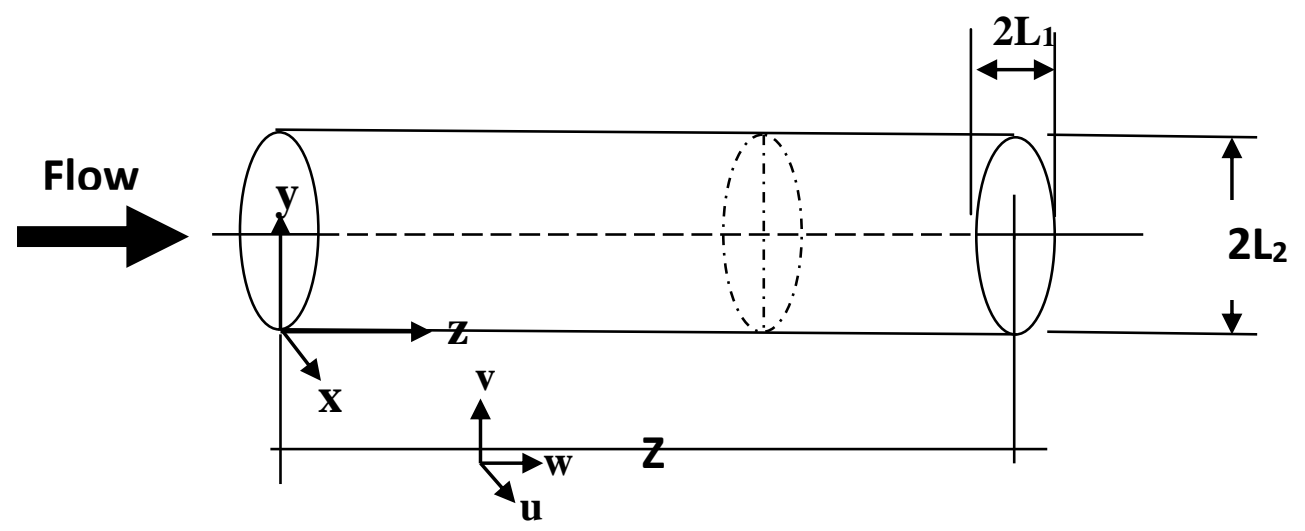

Figure 1.The physical model and coordinate system of the cylindrical pipe.

drop and fluid flow of LPG in cylindrical pipes of elliptic cross-sections. Lekner (2007) worked on viscous flow through pipes of various crosssections. Other researchers that have worked on elliptic cross-sections are Abdel-Wahed et al. (1984); McBain (1999); Silva et al. (1998); and Velusamy et al. (1995).

\section{MATHEMATICAL MODELLING}

\subsection{Description of physical model}

The physical model is shown in Figure 1. It consists of a straight cylindrical elliptic pipe with an unchanging cross-section. Its length is Z while semiminor and semi-major diameters are $L_{1}$ and $L_{2}$ respectively. The LPG is made to flow through the pipe.

\subsection{Basic assumptions}

The flow is assumed to be laminar, steady, three dimensional, and incompressible. The fluid is Newtonian with constant thermo-physical properties. The pipe is considered to be smooth, non-porous, rigid, and stationary.

\section{Conservation of Mass}

The conservation of mass equations is (FLUENT $6.3,2006)$ :

$\frac{\partial \rho}{\partial t}+\nabla \cdot(\rho \vec{v})=0$
Where $\vec{v}=(\mathrm{u}, \mathrm{v}, \mathrm{w})$ is the fluid velocity vectors, $\rho$ is the fluid density and $t$ is the time.

The conservation of momentum equation is (FLUENT 6.3, 2006):

$\frac{\partial}{\partial t}(\rho \vec{v})+\nabla \cdot(\rho \vec{v} \vec{v})=-\nabla P+\nabla \cdot(\overline{\bar{\tau}})+\rho g+\vec{F}$

Where $\mathrm{P}$ is the static pressure, $\overline{\bar{\tau}}$ is the stress tensor and $\vec{F}$ is the body force.

The stress tensor is given by Equation (3):

$\overline{\bar{\tau}}=\mu\left[\left(\nabla \vec{v}+\nabla \vec{v}^{T}\right)-\frac{2}{3} \nabla \cdot \vec{v} I\right]$

Where $\vec{v}$ is the velocity, $\mu$ is the molecular viscosity, $I$ is the unit tensor, and the second term on the right hand side is the effect of volume dilation.

The following boundary conditions were applied:

$\mathrm{u}=\mathrm{v}=0$ and $\mathrm{w}=\mathrm{w}_{0}=0.0186252$ for $\forall(\mathrm{x}, \mathrm{y})$

$\mathrm{u}=\mathrm{v}=\mathrm{w}=0$ for $\forall(\mathrm{x}, \mathrm{y}) \frac{x^{2}}{L_{1}^{2}}+\frac{y^{2}}{L_{2}^{2}}=1$

Parabolic outlet condition in $\mathrm{z}=\mathrm{c}$

Where $u, v$, and $w$ are the velocities along the $x, y$, and $z$ directions, respectively.

In the fully developed region, the velocity 
distribution of a laminar monophase fluid flow in cylindrical elliptic ducts with origin at $z$ is given as (Cade et al., 2010; Shah and Bhatti, 1987):

$w(x, y)=\frac{1}{2 \mu}\left(\frac{-\partial P}{\partial Z}\right) \frac{L_{1}^{2} L_{2}^{2}}{L_{1}^{2}+L_{2}^{2}}\left(1-\frac{y^{2}}{L_{1}^{2}}-\frac{x^{2}}{L_{2}^{2}}\right)$

Or $\frac{w}{w_{m}}=2\left(1-\frac{x^{2}}{L_{1}^{2}}-\frac{y^{2}}{L_{2}^{2}}\right)$

Where $w_{m}$ is the average velocity.

$$
w_{m}=\frac{1}{4 \mu}\left(\frac{-\partial P}{\partial Z}\right)\left(\frac{L_{1}^{2}}{1+\left(\frac{L_{1}}{L_{2}}\right)^{2}}\right)
$$

The cross-sectional area, A, perimeter, $p$, and the hydraulic diameter, $D_{h}$ are given as (Cade et al., 2010; Shah and Bhatti, 1987):

$$
\begin{aligned}
& A=\pi L_{1} L_{2} \\
& \hat{P}=4 L_{2} E\left(1-\left(\frac{L_{1}}{L_{2}}\right)^{2}\right) \\
& D_{h}=\frac{\pi L_{1}}{E\left(1-\left(\frac{L_{1}}{L_{2}}\right)^{2}\right)}
\end{aligned}
$$

Where $E$ is the complete elliptic integral of the second kind. Details of this equation can be seen elsewhere (Milne-Thomson, 1972).

The hydrodynamic entrance length, Lher, and the fFanning friction factor, $f_{f d r}$, in the fully developed region are given by (Cade et al., 2010; Shah and Bhatti, 1987):

$L_{h e r}=\frac{0.5132}{\left(1+\left(\frac{L_{1}}{L_{2}}\right)^{2}\right)}\left[\frac{E\left(1-\left(\frac{L_{1}}{L_{2}}\right)^{2}\right)}{\pi}\right]^{2} D_{h} \operatorname{Re}_{D h}$

$$
f_{f a r} \operatorname{Re}_{D h}=2\left(1+\left(\frac{L_{1}}{L_{2}}\right)^{2}\right)\left[\frac{\pi}{E\left(1-\left(\frac{L_{1}}{L_{2}}\right)^{2}\right)}\right]
$$

Reynolds number $=\operatorname{Re}_{D h}=\rho w_{m} D_{h} / \mu$

At the hydrodynamic entrance region, the apparent friction factor $\left(f_{\text {her }}\right)$ incorporates the combined effects of the wall shear and the change in the momentum flow rate due to the developing velocity profile, based on the total axial pressure drop from the duct inlet (at $z=0$ ) to the local point of interest. This is given as (Cade et al., 2010; Shah and Bhatti, 1987):

$\Delta P_{h e r}^{*}=\frac{P_{z=0}-P}{\rho w_{m}^{2} / 2}=f_{h e r} \frac{4 z}{D_{h}}$

The incremental pressure drop number in the hydro-dynamical developing region is:

$$
K(z)=\left(f_{\text {her }}-f_{f d r}\right) \frac{4 z}{D_{h}}
$$

Where $\mathrm{K}(\mathrm{z})$ is sometimes referred to as the incremental pressure defect. It increases monotonically from a value of zero at $z=0$ to a constant value $\mathrm{K}(\infty)$ at $\mathrm{z}>\mathrm{L}_{\text {her }}$ (Cade et al., 2010; Shah and Bhatti, 1987).

The equation that relates the incremental pressure drop number, friction factor, and the axial pressure drop is given by (Cade et al., 2010):

$\Delta P_{h e r}^{*}=f_{h e r} \operatorname{Re}_{D h}\left(\frac{4 z}{D_{h} \operatorname{Re}_{D h}}\right)=K(z)+f_{f d r} \operatorname{Re}_{D h}\left(\frac{4 z}{D_{h} \operatorname{Re}_{D h}}\right)$

The apparent friction factors and incremental pressure drop numbers can be expressed as:

$$
f_{h e r} \operatorname{Re}_{D h}=\frac{\Delta P_{h e r}^{*}}{4\left(\frac{4 z}{D_{h} \operatorname{Re}_{D h}}\right)}
$$

Where:

$$
\Delta P_{h e r}^{*}=\frac{2(1-\eta)(1+3 \eta)-(1+\eta)^{2} \ln \eta^{3}}{3(1+\eta)^{2}}
$$


And,

$$
K(z)_{h e r}=\frac{\left(3 \eta^{3}+9 \eta^{2}+21 \eta+7\right)(1-\eta)}{6(1+\eta)^{2}}
$$

Where $\eta$ is a boundary layer parameter which refers to the friction of the duct cross-section carrying inviscid flow (Shah and Bhatti, 1987).

The term $\eta$ is obtained implicitly from Equation (20) as a function of $z$ :

$16\left(1+\left(\frac{L_{1}}{L_{2}}\right)^{2}\right)\left[\frac{\pi}{E\left(1-\left(\frac{L_{1}}{L_{2}}\right)^{2}\right)}\right]^{2} \frac{z}{D_{h} \operatorname{Re}_{D h}}=$

$=\eta^{2}-1-\ln \eta^{2}$

The fully developed incremental pressure drop number, $K(\infty)$, for elliptic ducts is independent of the duct aspect ratio $\left(L_{1} / L_{2}\right)$. The value of $K(\infty)$ is recommended to be 1.26 for practical calculations(Cade et al., 2010).

The boundary layer parameter ( $\eta$ ) attains the value of zero as the limit of the flow becomes developed hydrodynamically and all the momentum transfer quantities asymptotically reduce to the known exact and fully developed values (Shah and Bhatti, 1987).

\section{NUMERICAL PROCEDURE}

Commercially available CFD software, code FLUENT (version 6.3.26), was used to simulate the 3D motion of fluid through the horizontal elliptic duct. The grids were generated using the ANSYS ICEM CFD (version 12.0.1) which is the preprocessing module of the FLUENT code. The geometry and the grid for the pipes were then imported into FLUENT. FLUENT uses the finite volume method. It can use both the structured and unstructured meshes. The geometries considered were cylindrical pipes of elliptic cross sections with lengths of $30 \mathrm{~m}$. For the solution control of the FLUENT, under the pressure-velocity coupling,
SIMPLE was used; under discretisation for pressure, standard was used; and, for momentum, first order upwind was used. Absolute convergence criterion of $10^{-10}$ was used for continuity and $x-, y-$ and $z-$ velocity components in the Navier-Stokes equation of FLUENT.

\section{NUMERICAL PROCEDURE}

\subsection{Numerical grid}

Figures 2 to 6 give the details of the grids used for the cylindrical pipe of elliptic cross section. The mesh is hexahedral. The final grids were obtained after several refinements called grid independent study. Table 1 gives the dimensions of the pipes used in the current work and the corresponding eccentricity of each pipe.

\subsection{Numerical validation}

Table 2 depicts the properties of the natural gas used for the validation of the current work. Pipe $1\left(L_{1}=L_{2}=0.1 \mathrm{~m}\right)$ was used for the simulation with velocity $w_{o}=0.1 \mathrm{~m} / \mathrm{s}$. The present numerical result for velocity, taken at distance of $25 \mathrm{~m}$ from the inlet, was compared with the analytic result of Shah and Bhatti (1987) and the numerical result of Cade et al. (2010). Figure 7 shows the comparison graphically. The result shows good agreement with error of $0.24 \%$, when compared with the result of Shah and Bhatti (1987) at $y=0$ which is the axis with maximum velocity. Table 3 compares the

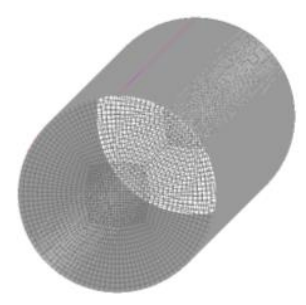

Figure 2. Details of circular grid with 456000 elements (Pipe 1).

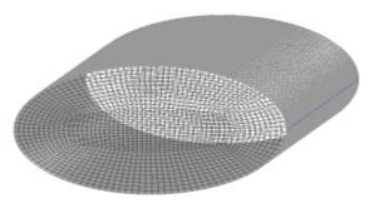

Figure 3. Details of elliptic grid 467161 elements (Pipe 2). 


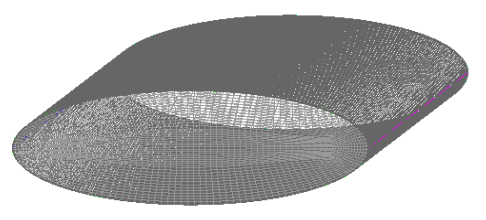

Figure 4. Details of elliptic grid with 343035 elements (Pipe 3)

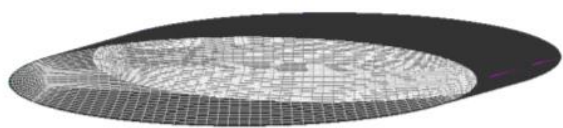

Figure 5 Details of elliptic pipe with 485817 elements (Pipe 4).

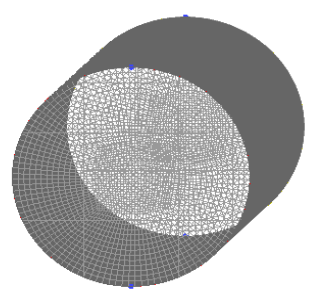

Figure 6. Details of elliptic pipe with 470000 elements (Pipe 5).

natural gas flow pressure drop between Cade et al. (2010), Shah and Bhatti (1987), and the current work for the purpose of validation. The range of error obtained from Cade et al. (2010) was found to vary between 4.77 and $20.33 \%$, when compared with result of Shah and Bhatti (1987) while the error for the current work varied between 0.58 and $13.5 \%$.

\subsection{Applications}

The physical properties of LPG used for the current work are shown in Table 4. It is worthy of note that the formula used in arriving at the dynamic viscosities and densities in Table 4 can be found in Rohsenow and Harnett (1973).

The result of the simulations of 100 per cent butane are shown from Figure 8 to Figure 19, while Figure 20 depicts the pressure drop results for varying percentages of butane/propane, which are the major constituents of LPG. Figures 8 and 9
Table 1. Dimensions of the pipes used in the current work.

\begin{tabular}{llll}
\hline Pipe & \multicolumn{3}{l}{ Pipe Dimensions(m) Eccentricity } \\
& $\mathrm{L}_{1}$ & $\mathrm{~L}_{2}$ & $\mathrm{E}$ \\
\hline 1 & 0.100000 & 0.100000 & 0.0000 \\
2 & 0.100000 & 0.150000 & 0.7453 \\
3 & 0.100000 & 0.300000 & 0.9428 \\
4 & 0.100000 & 0.500000 & 0.9798 \\
5 & 0.173205 & 0.173205 & 0.0000 \\
\hline
\end{tabular}

Table 2. Physical properties of the natural gas used in the validation (Cade et al., 2010).

\begin{tabular}{|l|l|}
\hline$\rho$ & $0.72\left(\mathrm{~kg} / \mathrm{m}^{3}\right)$ \\
\hline$\mu\left(1 \mathrm{~atm}\right.$ and $\left.20^{\circ} \mathrm{C}\right)$ & $1.1 \times 10^{-5}\left(\mathrm{~N} . \mathrm{s} / \mathrm{m}^{2}\right)$ \\
\hline
\end{tabular}

(pipe 1); Figures 12 and 13 (pipe 2); Figures 14 and 15 (pipe 3); Figures 16 and 17 (pipe 4); and Figures 18 and 19 (pipe 5) show the velocity field of the 100 per cent LPG gas phase at cross sections yx at $\mathrm{z}=5 \mathrm{~m}$ and $30 \mathrm{~m}$ respectively. In all cases, the velocity at the wall was zero, confirming the no-slip condition. The velocity increased from walls toward the center of the pipe and downstream as the fluid flowed from close to the inlet towards the outlet (at $5 \mathrm{~m}$ and $30 \mathrm{~m}$ ). The outlet velocity appeared to be at maximum. Edge effects were detected in pipes with large eccentricities, as reported by Cade et al. (2010) for large aspect ratios. This was

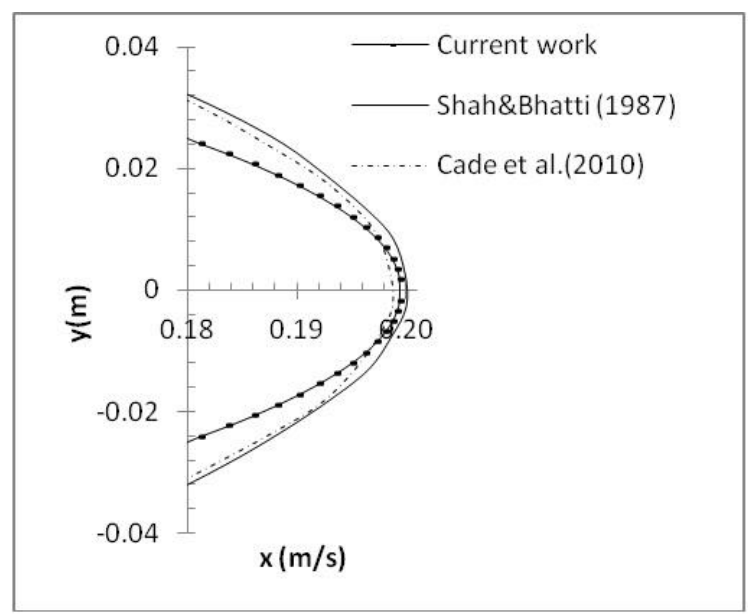

Figure 7. Graph of velocity distribution at $25 \mathrm{~m}$ along pipe 1. 
Table 3. Natural gas flow pressure drop obtained for validation of the current work.

\begin{tabular}{|c|c|c|c|}
\hline Eccentricity (e) & $\begin{array}{c}\text { Shah \& Bhatti (1987) } \\
\left(\mathrm{N} / \mathrm{m}^{2}\right)\end{array}$ & $\begin{array}{l}\text { Cade et al. (2010) } \\
\left(\mathrm{N} / \mathrm{m}^{2}\right)\end{array}$ & $\begin{array}{l}\text { Current work } \\
\left(\mathrm{N} / \mathrm{m}^{2}\right)\end{array}$ \\
\hline Pipe1 $=0.0000$ & 0.030599 & 0.032060 & 0.0307772 \\
\hline Pipe2 $=0.7454$ & 0.023265 & 0.025226 & 0.0237164 \\
\hline Pipe $3=0.9428$ & 0.018865 & 0.021516 & 0.0192670 \\
\hline Pipe4=0.9798 & 0.017926 & 0.021571 & 0.0203506 \\
\hline Pipe $5=0.0000$ & 0.012709 & 0.014347 & 0.0132434 \\
\hline
\end{tabular}

Table 4. Physical properties of the LPG used for the simulation.

\begin{tabular}{|c|c|c|c|}
\hline Butane (\%) & Propane (\%) & $\mu\left(\mathrm{x} 10^{-6}\right)\left(\mathrm{N} . \mathrm{s} / \mathrm{m}^{2}\right)$ & $\rho\left(\mathrm{kg} / \mathrm{m}^{3}\right)$ \\
\hline 100 & 0 & 2.460 & 7.000 \\
\hline 95 & 5 & 2.433 & 7.533 \\
\hline 90 & 10 & 2.405 & 8.010 \\
\hline 85 & 15 & 2.378 & 8.435 \\
\hline 80 & 20 & 2.350 & 8.811 \\
\hline
\end{tabular}

revealed in pipe 4 at a distance of $z=5 \mathrm{~m}$.

Figure 10 and Figure 11 show typical velocity and pressure variations, respectively, in the axial plane yz along pipe 1 . The velocity increased towards the centre and along the plane, while the pressure decreased towards the downstream along the plane.

Figure 20 shows the result of pressure drop for various eccentricities at different percentages of butane/propane. It reveals that pipe 1 had the highest value of pressure drop for a particular percentage of butane/propane, followed by pipe 2 , pipe 3 , pipe 4 , and pipe 5 in descending order. For comparison of pressure drop between two ducts of the same cross sectional area, pipe $3(e=0.9428)$ and pipe $5(\mathrm{e}=0.0)$ were compared. Pipe 3 was elliptic while pipe 5 was circular. The result indicated that the pressure drop in the elliptic pipe was $0.0022836 \mathrm{~Pa}$ while that of the circular pipe was $0.001569387 \mathrm{~Pa}$ at 100 per cent butane. For all percentages of butane to propane, the pressure drop of pipe 3 was higher than that of pipe 5. For 100 percent butane, the pressure drop was higher by $45.5 \%$. This implies that, in order to maintain the flow of LPG in pipe 3, the pressure drop has to be higher than that of the pipe 5 by the said percentage for the same flow rate.

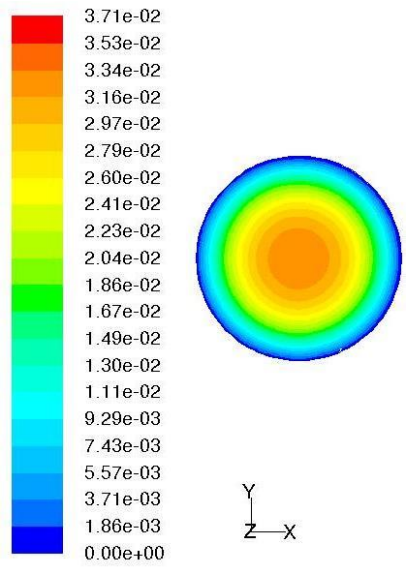

Figure 8 . Velocity distribution of $100 \%$ butane in the cross-section yx in $z=5 m$ along Pipe 1.

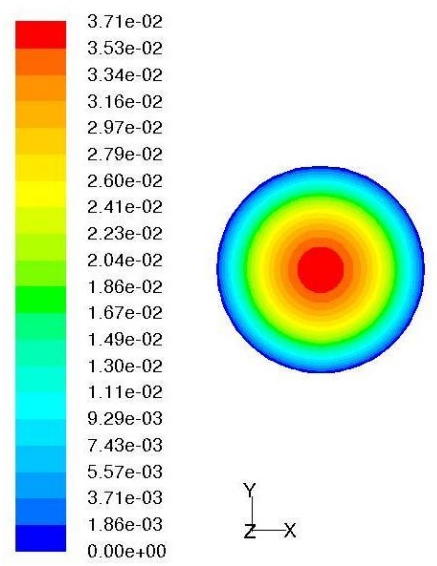

Figure 9. Velocity distribution of $100 \%$ butane in the cross-section yx in $z=30 \mathrm{~m}$ along Pipe 1. 


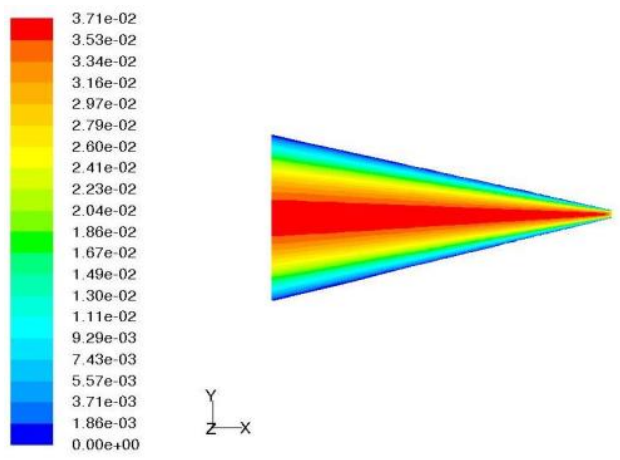

Figure 10. Typical Velocity distribution for $100 \%$ butane in the axial plane yz along Pipe 1.

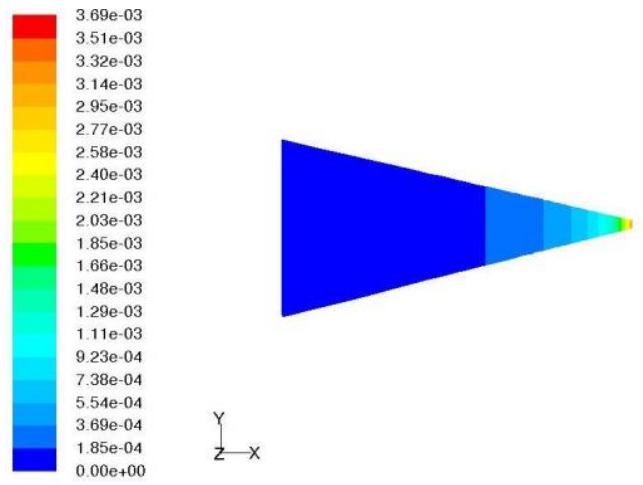

Figure 11. Typical Pressure distribution for $100 \%$ butane in the axial plane yz along Pipe 1.

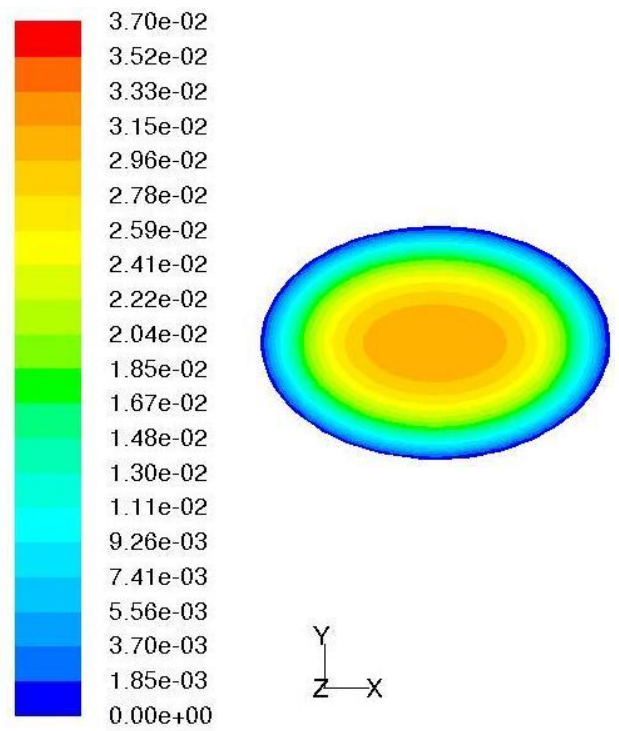

Figure 12. Velocity distribution of $100 \%$ butane in the cross-section yx in $z=5 \mathrm{~m}$ along Pipe 2 .

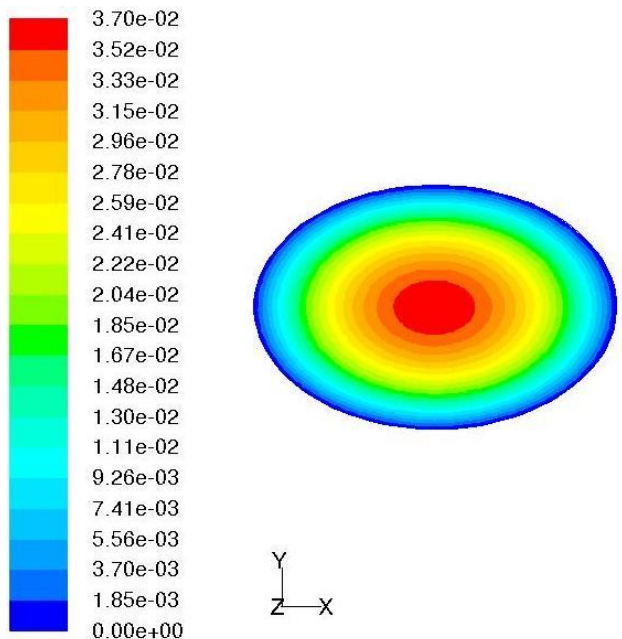

Figure 13. Velocity distribution of $100 \%$ butane in the cross-section yx in $z=30 \mathrm{~m}$ along Pipe 2.

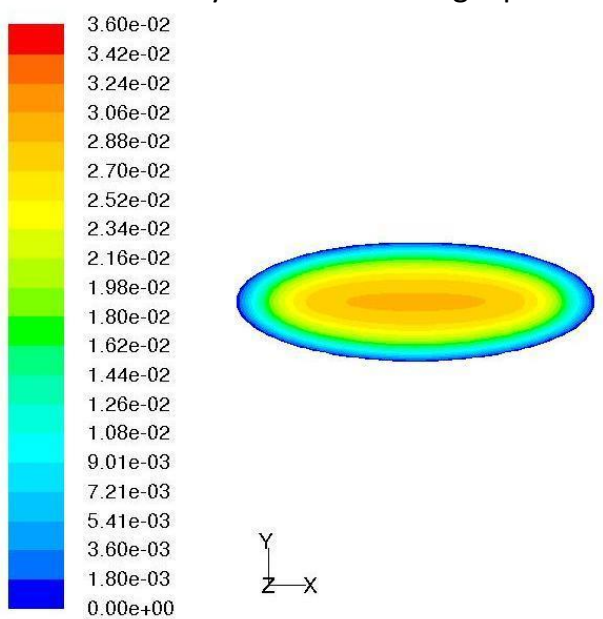

Figure 14 . Velocity distribution of $100 \%$ butane in the cross-section yx in $z=5 \mathrm{~m}$ along Pipe 3 .

The pressure drop variation of LPG (at $100 \%$ butane) was observed to be an order of magnitude less than that observed for natural gas flowing with the same Reynolds number. For example, for pipe 2 the pressure drop for $100 \%$ butane was 0.002811 $\mathrm{Pa}$, while for natural gas it was $0.02372 \mathrm{~Pa}$. The implication of this is that a lower pressure drop is needed to maintain the LPG flow in the pipes in comparison to the natural gas flow in the pipe of the same dimension. Another observation from Figure 20 is that, as eccentricity increases, the pressure drop reduces for all percentages of butane/propane mix. In all pipes, the lowest pressure drop was experienced in LPG with 100/0 $\%$ (butane/propane) contents. Table 5 shows the correlations developed from Figure 20 for pressure drop along the pipe and the butane percentile in the composition. 


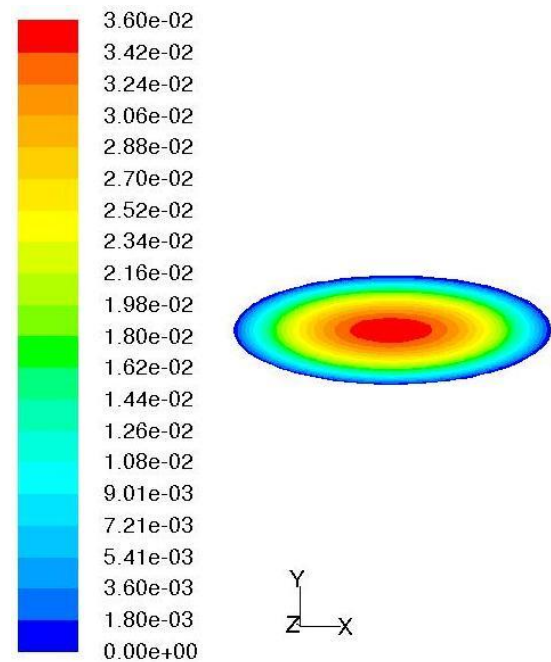

Figure 15 . Velocity distribution of $100 \%$ butane in the cross-section yx in $z=30 \mathrm{~m}$ along Pipe 3 .

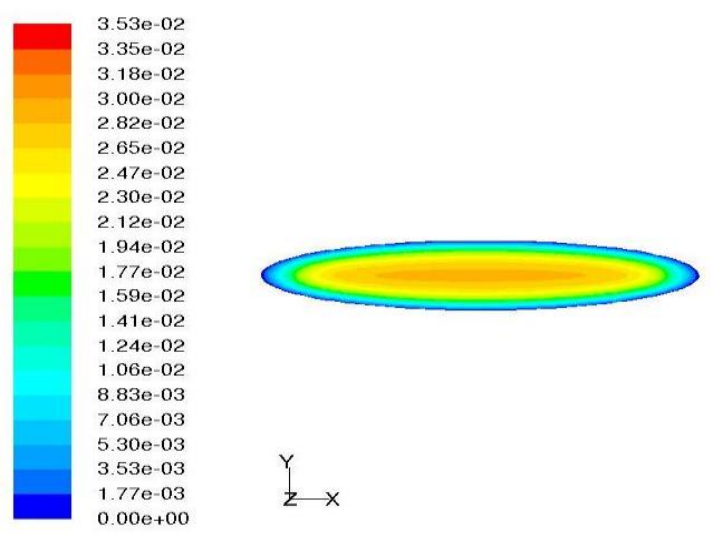

Figure 16 . Velocity distribution of $100 \%$ butane in the cross-section yx in $z=5 \mathrm{~m}$ along Pipe 4 .

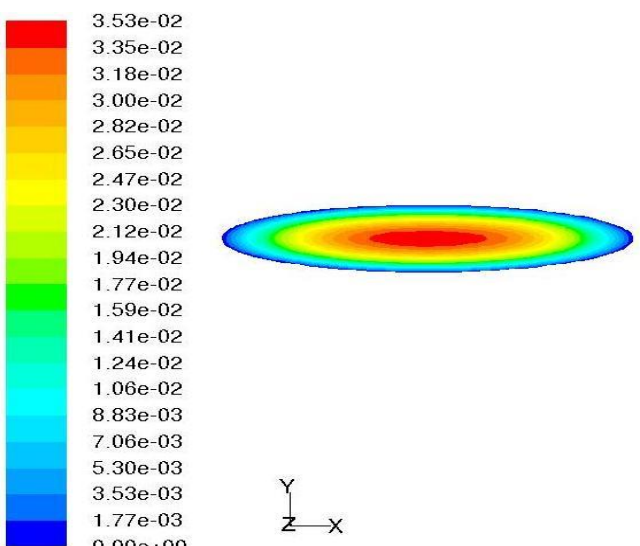

Figure 17. Velocity distribution of $100 \%$ butane in the cross-section yx in $z=30 \mathrm{~m}$ along Pipe 4 .

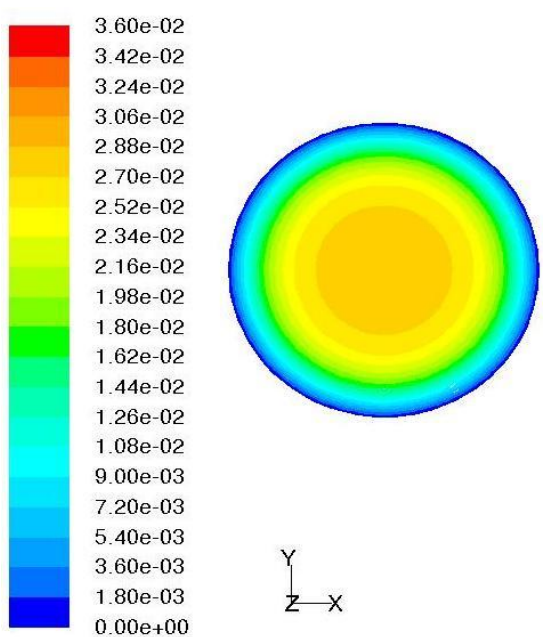

Figure 18 . Velocity distribution of $100 \%$ butane in the cross-section $y x$ in $z=5 \mathrm{~m}$ along Pipe 5 .
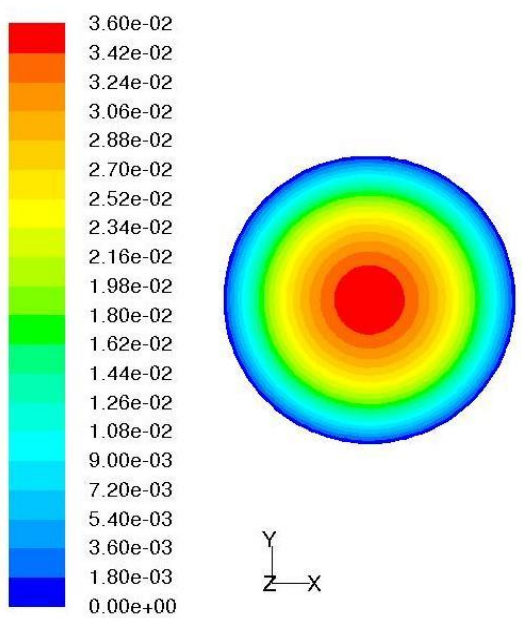

Figure 19. Velocity distribution of $100 \%$ butane in the cross-section yx in $z=30 \mathrm{~m}$ along Pipe 5 .

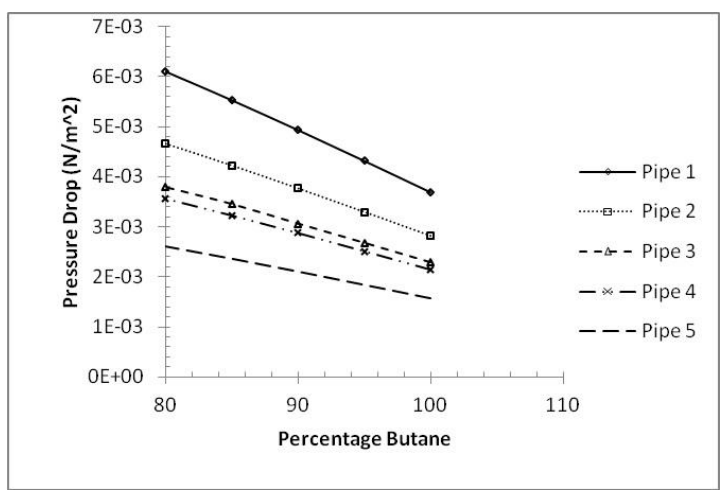

Figure 20. Pressure drop variations of eccentricity and percentage butane to propane 
Table 5.Correlations of pressure drop against percentage butane content.

\begin{tabular}{ccc}
\hline Pipe name & Reynolds number & Correlation equation \\
\hline Pipe 1 & 1309.1 & $\mathrm{P}=0.0001 \mathrm{C}+0.0159$ \\
Pipe 2 & 1555.3 & $\mathrm{P}=-9 \mathrm{e}-05 \mathrm{C}+0.0121$ \\
Pipe 3 & 1846.3 & $\mathrm{P}=-8 \mathrm{e}-05 \mathrm{C}+0.0099$ \\
Pipe 4 & 1957.5 & $\mathrm{P}=-7 \mathrm{e}-05 \mathrm{C}+0.0092$ \\
Pipe 5 & 2267.1 & $\mathrm{P}=-5 \mathrm{e}-05 \mathrm{C}+0.0068$ \\
\hline
\end{tabular}

Where $\mathrm{P}=$ Pressure drop and $\mathrm{C}=\%$ Butane content

\section{CONCLUSIONS}

The software FLUENT has been used to predict the 3D fluid flow and pressure drop in cylindrical pipes of elliptic cross-section. Results showed that pressure drop for LPG flow in elliptic pipes was higher than that of circular pipes of the same crosssectional area. The pressure drop in pipes with natural gas flow is an order of magnitude greater than the pressure drop in LPG flow in elliptic pipes. Based on the above-mentioned, one can conclude that as eccentricity increases, the pressure drop reduces for LPG flow in cylindrical elliptic pipes. The velocity of the LPG flow decreases as the eccentricity gets larger.

It is recommended, based on the results, that the $1.4 / 98.5 \%$ propane/ butane LPG composition be encouraged in Nigeria to reduce pumping power requirement. Further work is ongoing to compute the heat transfer characteristics of the LPG flow in pipelines.

\section{ACKNOWLEDGMENTS}

The second author wishes to acknowledge the Centre for Cooperation in Science and Technology among Developing Societies (CCSTDS- Fellowship no: D.O./CCSTDS/2685/2010), India, and the Indian Institute of Technology, Madras (IITM), for their financial support and the opportunity to do a major part of this work in India.

\section{REFERENCES}

Abdel-Wahed, R. M.; Attia, A. E.; Hifni, M.A. Experiments on laminar flow and heat transfer in an elliptical duct, International Journal of Heat and Mass Transfer, v. 27, n. 2, p. 2397-2413, 1984.http://dx.doi.org/10.1016/0017-9310(84)90098-X

Agboade, B. The International Comparative Legal Guide to Gas Regulation 2012, London, Global Legal Group Ltd, 215p.

Bhatti, M. S. Laminar flow in the entrance region of elliptical ducts, American Society of Mechanical Engineers, Applied Mechanics, Bioengineering, and Fluids Engineering Conference, Houston, TX, June 20-22, 1983.

Cade, M. A.; Lima, W. C.; Farias-Neto, P. B.; Lima, A. G. B. Natural gas laminar flow in elliptic cylindrical pipes: A numerical study, Brazilian Journal of Petroleum and Gas, v. 4, n. 1, p. 019033, 2010.

Chikwendu, C. C. Change-over from Kerosene to LPG use - A family case study, Energia: International Network on Gender and Sustainable Energy, January 2011.

Fluent 6.3, User manual, 2006.

Lasode, O.A., Popoola, O.T., Prasad, B.V.S.S.S. Numerical study of liquefied petroleum gas laminar flow in cylindrical elliptic pipes, WASET International Conference on Fluid Mechanics, Heat Transfer and Thermodynamics (ICFMHTT 2013), Copenhagen, June 13-14, 2013. 
Lekner, J., Viscous flow through pipes of various cross-sections, European Journal of Physics, v. 28, p. 521-527, 2007.http://dx.doi.org/10.1088/0143$\underline{0807 / 28 / 3 / 014}$

LPG - Liquefied Petroleum Gas. Available at: http://www.ripack.in/pdf/LPG.PDF Accessed on: 12 December 2012.

McBain, G.D. Fully developed laminar buoyant flow in vertical cavities and ducts of bounded section, Journal of Fluid Mechanics, v. 401, p. 365377, 1999.

http://dx.doi.org/10.1017/S0022112099006783

Milne-Thomson, L. M. Elliptic Integrals, In Handbook of Mathematical Functions, Eds. Abramowitz, M.; Stegun, I. A. $9^{\text {th }}$ Edition Dover Publications Inc., New York, 1972. 1046p.

Olorunmaiye, J. A. Tuning of valveless pulsed combustor running on Nigerian Liquefied Petroleum gas, Centrepoint: A Journal of Intellectual Scientific and Cultural Interest, Science Edition, v.7, n. 1, p. 1-15, 1997.

Rohsenow, W. M.; Harnett, J. P. Handbook of Heat Transfer, New York, McGraw-Hill Book Company, 1973.

Shah, R. K.; Bhatti, M. S. Laminar convective heat transfer in ducts, In Handbook of SinglePhase Convective Heat Transfer, Eds. KakaÇ, S., Aung, W ., Shah, R. K., New York, USA, John Wiley and Sons, 1987, 3.1p.
Silva, R. J.; Valle, R. M.; Ziviani, M. Numerical hydrodynamic and thermal analysis of laminar flow in curved elliptic and rectangular ducts, International Journal of Thermal Sciences, v. 38, p.585-594, 1999.http://dx.doi.org/10.1016/S0035$\underline{3159(99) 80038-5}$

TCPA- Texas Comptroller of Public Account, Energy report, (2008). Available at: http://www.window.state.tx.us/specialrpt/energy/ pdf/06-LPG.pdf, Accessed on: 12 December 2012.

Velusamy, K.; Garg, V. K. Entrance flow in elliptical ducts, International Journal for Numerical Methods in Fluids, v.17, p. 1079-1096, 1993.http://dx.doi.org/10.1002/fld.1650171205

Velusamy, K.; Garg, V.K.; Vaidyanathan, G. Fully developed flow and heat transfer in semi-elliptical ducts, International Journal of Heat and Fluid Flow, v. 16, p.145-152, 1995.

http://dx.doi.org/10.1016/0142-727X(94)00019-9

WBOGD -World Bank Oil and Gas Division, World LPG Gas Association report, 2001. 